\title{
Communication between Dutch rheumatologists and occupational physicians in the occupational rehabilitation of patients with rheumatic diseases
}

\author{
P D M de Buck, R J van Amstel, P C Buijs, J H W Maasen, F J H van Dijk, J M W Hazes, \\ T P M Vliet Vlieland
}

Background: Rheumatic diseases are a major cause of permanent work disability. In the process of occupational rehabilitation several health professionals may have a role.

Objective: To assess the quality and quantity of communication and cooperation between Dutch rheumatologists and occupational physicians.

Methods: A postal survey among 187 Dutch rheumatologists.

Results: $153 / 187$ rheumatologists $(82 \%)$ returned the questionnaire. They considered reducing pain and fatigue to be their major responsibility in the process of occupational rehabilitation, followed by improving work participation $(68 / 153(44 \%))$ and quality of work $(55 / 153(36 \%))$. Although $112 / 153(73 \%)$ of the rheumatologists judged the communication and cooperation with occupational physicians as reasonable to good, $119 / 153(78 \%)$ of them were willing to improve the collaboration. Perceived bottlenecks mentioned were a lack of clarity about the occupational physician's position and activities, and the absence of practice guidelines. The most important prerequisites for improvement were found to be guarantees about the occupational physician's professional independence and more clarity about the competence of the occupational physicians and how they used the information provided.

Conclusion: Dutch rheumatologists are willing to improve cooperation and communication with occupational physicians. The perceived lack of clarity about their mutual tasks appears to be a major obstacle. Thus the development of a joint education programme and a guideline for occupational rehabilitation in rheumatic diseases may be appropriate first steps towards improvement.

$\mathrm{R}^{\mathrm{s}}$ heumatic diseases are a major cause of work disability and place a huge financial burden on the individual as well as on society. ${ }^{2}$ In addition, the non-economic impact of work disability on a person and his or her family is substantial. ${ }^{3}$ Patients with a rheumatic disease who have a health related problem in their performance at work receive non-uniform guidance as the organisation and availability of care vary among countries. ${ }^{56}$ This diversity is seen in the role and availability of individual health professionals as well as multidisciplinary facilities such as occupational rehabilitation teams. $^{78}$

In the Dutch occupational healthcare system, both occupational physicians and general practitioners or medical specialists play a part in the guidance of patients with a health related problem in their performance at work. Occupational physicians are linked to Occupational Health Services, with which all companies are legally obliged to have a contract since January 1998. At this time, $96 \%$ of companies have met this requirement. The guidance offered by occupational physicians is mainly aimed at preventing and diminishing sick leave and improving return to work. ${ }^{9}$

Successful occupational rehabilitation in rheumatic diseases requires a working partnership between the patient, the occupational physician, the rheumatologist, other health professionals, and the employer. Recent studies have shown that cooperation and communication between the different physicians who participate in occupational rehabilitation need to be improved. ${ }^{11} 12$

The objective of this study was to assess both the quality and the quantity of communication and cooperation between Dutch rheumatologists and occupational physicians and to list suggestions for improvement.

\section{METHODS}

All 187 Dutch rheumatologists and rheumatologists in training (further referred to as rheumatologists) who were members of the Dutch Society for Rheumatology on 1 September 1999 received a postal survey in October 1999. The survey used was based on a questionnaire developed by TNO Work and Employment, Hoofddorp, The Netherlands. This questionnaire was designed to list among general practitioners, medical specialists, and occupational physicians the frequency and reasons for contacts and the perceived bottlenecks in, and prerequisites for, improvement of cooperation. ${ }^{13}$ The adjusted survey for rheumatologists comprised a total of 29 questions. The first seven questions were designed specifically for rheumatologists. In the survey the following definition of a working problem was used: The experience of limitations in the performance of a paid job due to a rheumatic disease, which may lead or may have led to absenteeism from work.

\section{RESULTS}

A total of 153/187 (82\%) rheumatologists returned the survey. The mean age of the responders was 44.4 years (SD 7.7), 65\% were male and 35\% worked in an academic hospital.

Actual rheumatological practice and collaboration with occupational physicians in the case of working problems

Overall, most rheumatologists ask their patients about their working situation regularly ( $77 \%$ often, $22 \%$ sometimes, and $1 \%$ never). Most rheumatologists indicated that they would actually refer their patients with a working problem to the rheumatology nurse practitioner $(65 \%)$, the occupational therapist $(44 \%)$, the physical therapist $(34 \%)$, the social worker $(22 \%)$, or a vocational rehabilitation team $(25 \%)$. In 


\begin{tabular}{|c|c|c|c|c|}
\hline \multirow{2}{*}{$\begin{array}{l}\text { Contacts between rheumatologists and occupational physicians } \\
\text { Frequency of contacts over the past } 4 \text { weeks, median (range) }(n=153)\end{array}$} & \multicolumn{4}{|c|}{ Responders } \\
\hline & \multicolumn{4}{|c|}{$2(1-25)$} \\
\hline \multicolumn{5}{|l|}{ Initiative for making contact by the rheumatologists $(n=153)$ : } \\
\hline Never & \multicolumn{4}{|l|}{41} \\
\hline Seldom & \multicolumn{4}{|l|}{51} \\
\hline Often & \multicolumn{4}{|l|}{8} \\
\hline Always & \multicolumn{4}{|l|}{0} \\
\hline \multicolumn{5}{|l|}{ Contact is made by rheumatologists ( $n=85$ ) by: } \\
\hline Telephone only & \multicolumn{4}{|l|}{15} \\
\hline Mail only & \multicolumn{4}{|l|}{15} \\
\hline More by telephone than by mail & \multicolumn{4}{|l|}{40} \\
\hline More by mail than by telephone & \multicolumn{4}{|l|}{20} \\
\hline Both in equal proportions & \multicolumn{4}{|l|}{9} \\
\hline Reasons given by rheumatologists for occupational physicians to contact them $(n=153)$ : & Often & Sometimes & Seldom & Never \\
\hline To get more information about patients' complaints & 90 & 8 & 1 & 1 \\
\hline To get a prognosis about the duration of work incapacity & 78 & 15 & 6 & 1 \\
\hline To get more information about current treatment & 75 & 17 & 5 & 3 \\
\hline To get information about disabilities of the patient related to return to work & 54 & 31 & 11 & 5 \\
\hline To get additional information needed for a medical examination & 9 & 31 & 25 & 34 \\
\hline To plan a joint strategy for treatment and vocational rehabilitation & 6 & 17 & 37 & 40 \\
\hline To get additional information needed for filling in a report & 4 & 7 & 16 & 73 \\
\hline To make an annotation about current treatment by the rheumatologist & 1 & 4 & 18 & 78 \\
\hline To shorten the waiting list & 0 & 10 & 11 & 79 \\
\hline To suggest a second opinion & 0 & 4 & 2 & 68 \\
\hline Overall judgment of the contacts with occupational physicians $(n=140)$ : & $\%$ & & & \\
\hline Good & 34 & & & \\
\hline Reasonable & 39 & & & \\
\hline Fair & 22 & & & \\
\hline Bad & 5 & & & \\
\hline
\end{tabular}

contrast with the availability of the mentioned health professionals (89-100\%), vocational rehabilitation teams were available to only $28 \%$ of the rheumatologists.

Rheumatologists indicated that reducing pain and fatigue was considered to be fully (66\%) or partially (32\%) part of their task. Improving work participation and quality of work, shortening ill health and giving guidance on ill health retirement were indicated as fully part of their task by $44 \%$ of the rheumatologists.

Table 1 presents the frequency of contacts between rheumatologists and occupational physicians, the way contact is made and by whom, and the overall judgment of the contacts and the reasons for contacting the rheumatologist by the occupational physician. Only $18 \%$ of the rheumatologists were familiar with the contents of the guidelines of the Royal Dutch Medical Association (KNMG) about the exchange of sociomedical information, ${ }^{14} 42 \%$ had heard about them, and $40 \%$ were not familiar with them. Of the $18 \%$ of the rheumatologists who were familiar with the guidelines, 57\% said they worked well in daily practice.

Figure 1 presents four of 11 probable bottlenecks, which were mentioned as important by more than half of the responders. The other seven bottlenecks presented which were considered to be important bottlenecks by fewer then 35\% of the rheumatologists were not knowing the occupational physicians personally, the fear of a patient pressing charges when information is provided orally without prior consent or when the occupational physician is passing on the provided information to a third party, a lack of financial compensation for written information, the occupational physician's only goal is to get the patient back to work as soon as possible, rheumatologists have a general lack of knowledge about work related disorders, commercialisation of Occupational Health Services, and lack of a relationship based on mutual trust between occupational physicians and their patients.

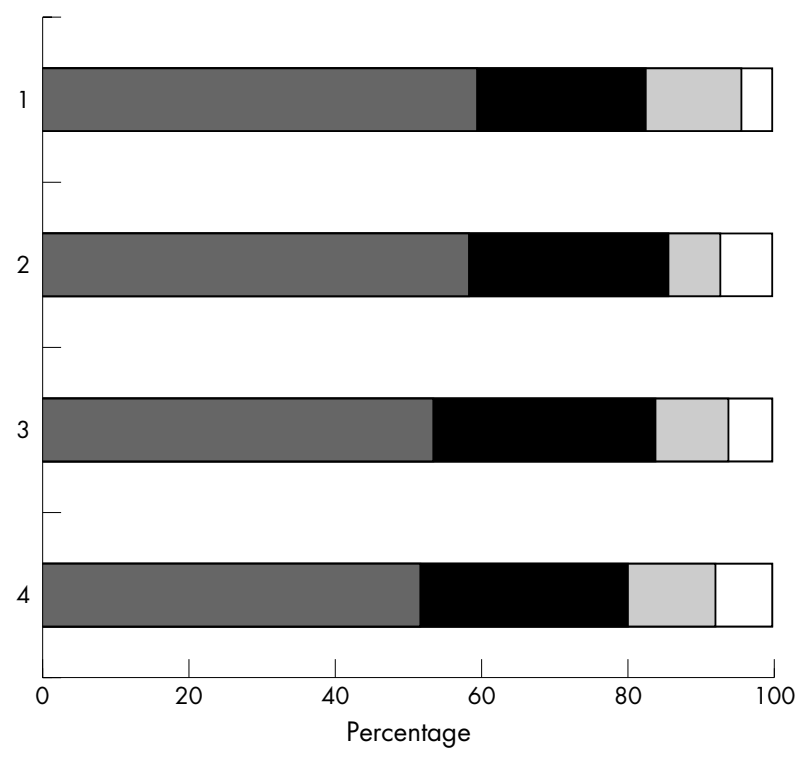

Important bottleneck

Less important bottleneck

$\square$ No bottleneck

$\square$ No opinion

Figure 1 Perceived bottlenecks in the communication. Eleven probable bottlenecks were listed. Four bottlenecks mentioned by more than half of the responders to be important are presented here: 1 , information provided may be used with the aim of rehabilitation but also for legislation of absenteeism; 2, occupational physicians may serve employers more than employees; 3 , lack of clarity about occupational physicians' tasks; 4, no guidelines about cooperation in the process of vocational rehabilitation. 


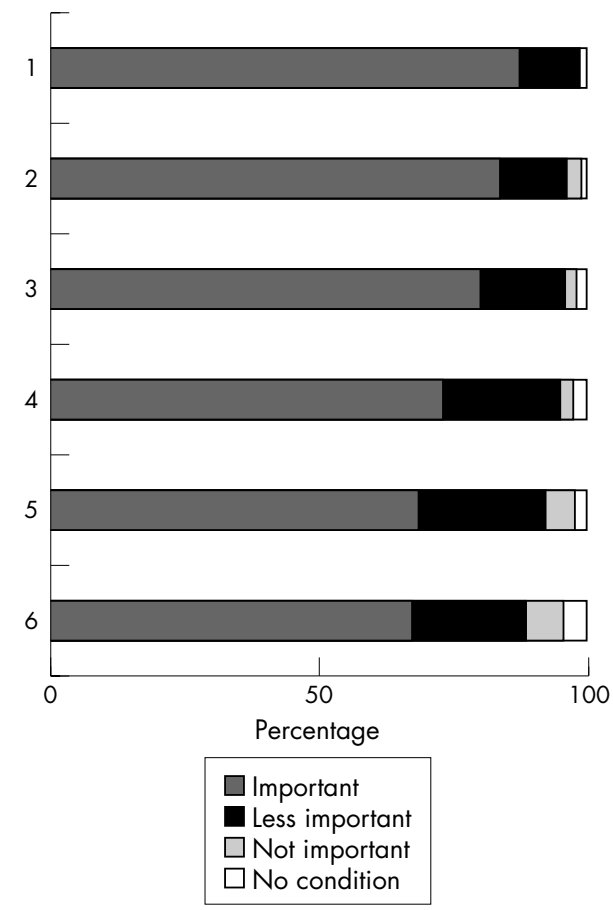

Figure 2 Ten prerequisites for improvement were listed. Six prerequisites for improvement mentioned to be important by more than half of the responders are presented here: 1 , overall health status of the patient must be the major issue; 2 , professional independence of occupational physicians; 3, guarantees about the use of given information; 4 , specificity about the abilities of occupational physicians; 5 , clarity about the goal of information provided; 6, guidelines about indication for cooperation, communication, and job delineation within the vocational rehabilitation process

\section{Prerequisites for improvement of collaboration with occupational physicians}

Most rheumatologists stated that it was important to improve cooperation with occupational physicians (78\%). Cooperation is already sufficient according to $6 \%$ of the responders, $7 \%$ said they did not need better cooperation because all the information could be provided by the patients themselves, and $9 \%$ of the rheumatologists thought that better cooperation was only needed in the early stages of rheumatic diseases. In the survey 10 prerequisites for improvement of cooperation with occupational physicians were listed. Figure 2 presents the six conditions for improvement which were mentioned as important by most of the rheumatologists. The four prerequisites for improvement which were mentioned by less than $43 \%$ of the rheumatologists were the possibility for communication between rheumatologists and occupational physicians without the patient's prior consent, a financial compensation for providing written information, a special budget to pay emergency consultation on request of the occupational physician, and the organisation of special meetings to get to know each other.

\section{DISCUSSION}

This study indicates that Dutch rheumatologists feel it is necessary to improve cooperation and communication with occupational physicians. However, the perceived lack of clarity about their mutual tasks appears to be a major obstacle.

This study was limited to the views of rheumatologists, as the opinions of occupational physicians have already been examined in a previous study. ${ }^{11}$ In that study, more than $80 \%$ of 232 occupational physicians also indicated a willingness to improve cooperation with other doctors.
Apart from lessening the burden of disease by treating pain and fatigue, rheumatologists see it also as part of their task to improve the quality of work, to decrease the duration of sick leave, and to prevent permanent work disability. In the light of this willingness to contribute actively to the occupational rehabilitation process, it is striking that cooperation between rheumatologists and occupational physicians is currently rather one sided. It appeared that for most contacts, information is provided by rheumatologists on request of the occupational physician only. These findings are in accordance with the results of a previous study among other medical specialists. Whereas rheumatologists and other specialists (neurologists, orthopaedic surgeons, and psychiatrists) seldom or never take the initiative to contact an occupational physician, rehabilitation specialists appeared to take the initiative for contact far more often. ${ }^{113}$

The rather passive role of rheumatologists so far may possibly be explained by a number of factors. Rheumatologists all mention the lack of information about the occupational physician's position and activities and the absence of guidelines or protocols about cooperation and communication, and existing guidelines appear to be known to only a few rheumatologists. The bottlenecks in the communication as perceived by rheumatologists are largely similar to the obstacles mentioned by other medical specialists. ${ }^{113}$ Occupational physicians, on the other hand, have indicated in a previous study that medical specialists have too little knowledge of Occupational Health Services and relevant legislation, do not know what they can expect from occupational physicians, and do not take into account their patients' jobs.

In the Netherlands the problem of insufficient cooperation and communication between occupational physicians, general practitioners, and medical specialists has been acknowledged by several parties, including health policy makers. General practitioners and occupational physicians subscribed to a consensus statement to improve cooperation and communication. The Dutch Government gave a financial grant for postgraduate courses, regional projects, and implementation of guidelines. The results of the present and previous studies underline the need to develop common concepts and guidelines between medical specialists and occupational physicians also. A study group has been formed comprising chairmen of the Society of Medical Specialists and the Dutch Organisation of Occupational Physicians. They have agreed to develop specific education programmes, common guidelines, and local experiments. The results of our study emphasise the need for rheumatologists to join in actively with the initiatives already taken.

\section{Authors' affiliations}

P D M de Buck, J M W Hazes, ${ }^{*}$ T P M Vliet Vlieland, Department of Rheumatology and Medical Decision Making, Leiden University Medical Centre, The Netherlands

R J van Amstel, P C Buijs, J H W Maasen, TNO Work and

Employment Hoofddorp, The Netherlands

J H W Maasen, Occupational Health Service Leiden University, The Netherlands

F J H van Dijk, Department of Occupational and Environmental Health, Coronel Institute, Academic Medical Centre University of Amsterdam, The Netherlands

*Current address: Department of Rheumatology, University Hospital Rotterdam, The Netherlands.

Correspondence to: Dr P D M de Buck, Leiden University Medical Centre, Department of Rheumatology, C4-R, PO Box 9600, 2300 RC Leiden, The Netherlands; pdmdebuck@lumc.nl

Accepted 20 June 2001

\section{REFERENCES}

1 Cooper NJ. Economic burden of rheumatoid arthritis: a systematic review. Rheumatology (Oxford) 2000;39:28-33. 
2 Barrett EM, Scott DG, Wiles NJ, Symmons DP. The impact of rheumatoid arthritis on employment status in the early years of disease: a UK community-based study. Rheumatology (Oxford) 2000;39:1403-9.

3 van Jaarsveld $\mathrm{CH}$, Jacobs JW, Schriivers AJ, Albada-Kuipers GA, Hofman DM, Biilsma JW. Effects of rheumatoid arthritis on employment and social participation during the first years of disease in the Netherlands. Br J Rheumatol 1998;37:848-53.

4 Young A, Dixey J, Cox N, Davies P, Devlin J, Emery P, et al. How does functional disability in early rheumatoid arthritis (RA) affect patients and their lives? Results of 5 years of follow-up in 732 patients from the early RA study (ERAS). Rheumatology (Oxford) 2000;39:603-11.

5 Lehnert G, Wrbitzky R. Occupational health in Germany and other countries of the European Union. Int J Occup Med Environ Health $1998 ; 11: 9-18$

6 Franco G. Occupational physicians' education and training across European union countries. Int Arch Occup Environ Health 1999;72:338-42.

7 Straaton KV, Harvey M, Maisiak R. Factors associated with successful vocational rehabilitation in persons with arthritis. Arthritis Rheum 1992;35:503-10.
8 Hulsemann JL. Cooperation between the family physician, rheumatologist, hospital and rehabilitation clinic. Contribution of regional cooperative rheumatic disease centers for total quality management. Z Rheumatol 1998;57:424-7

9 van Dijk FJ, Prins R. Occupational health care and work incapacity: recent developments in the Netherlands. Occup Med (Lond) 1995;45:159-66

10 van Dijk F. The occupational physician, expert opinion and position as medical specialist. Tijdschrift voor Bedrijfs-en verzekeringsgeneeskunde 1997; 5:24-31.

11 Buijs $\mathbf{P}$, van Amstel R, van Dijk F. Dutch occupational physicians and general practitioners wish to improve cooperation. Occup Environ Med 1999:56:709-13

12 de Bono AM. Communication between an occupational physician and other medical practitioners - an audit. Occup Med (Lond) 1997;47:349-56.

13 van Amstel R, Buijs P. Dutch medical specialists and their co-operation with occupational physicians in vocational rehabilitation, part 2. The Netherlands: TNO Work and Employment Hoofddorp, 2000.

14 Royal Dutch Medical Association Manual. Utrecht, the Netherlands: KNMG, 1992.

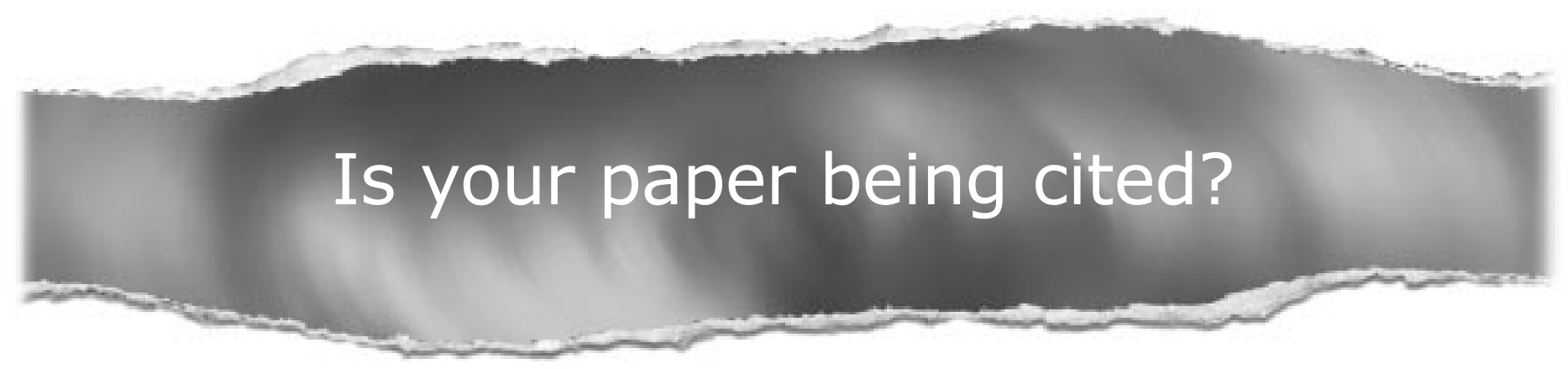

CiteTrack service

CiteTrack will alert you by email whenever new content in Annals of the Rheumatic Diseases or a participating journal is published that matches criteria you want to track

Topics: Tell CiteTrack which words or subjects to watch for in new content Authors: Be alerted whenever key authors you are following publish a new paper Articles: Know whenever a paper of interest to you is referenced by another paper

\section{www.annrheumdis.com}

